\title{
A fortuna crítica de
}
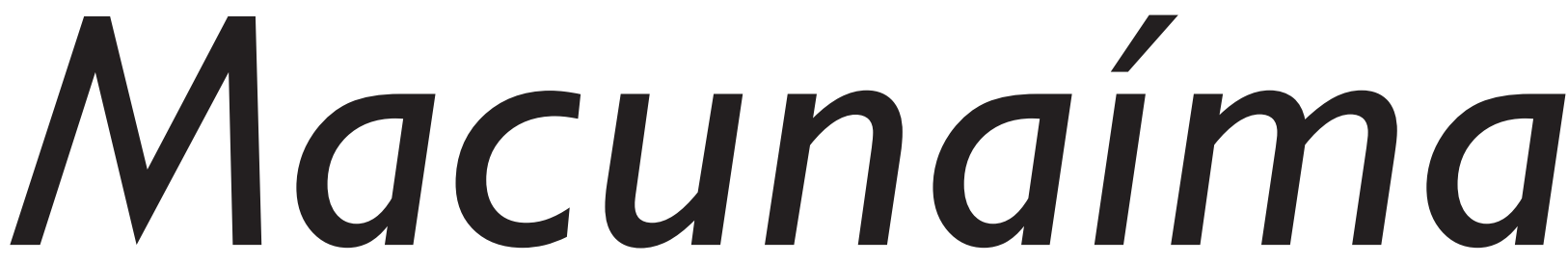

JO SÉ DE PAULA RAMOS JR.

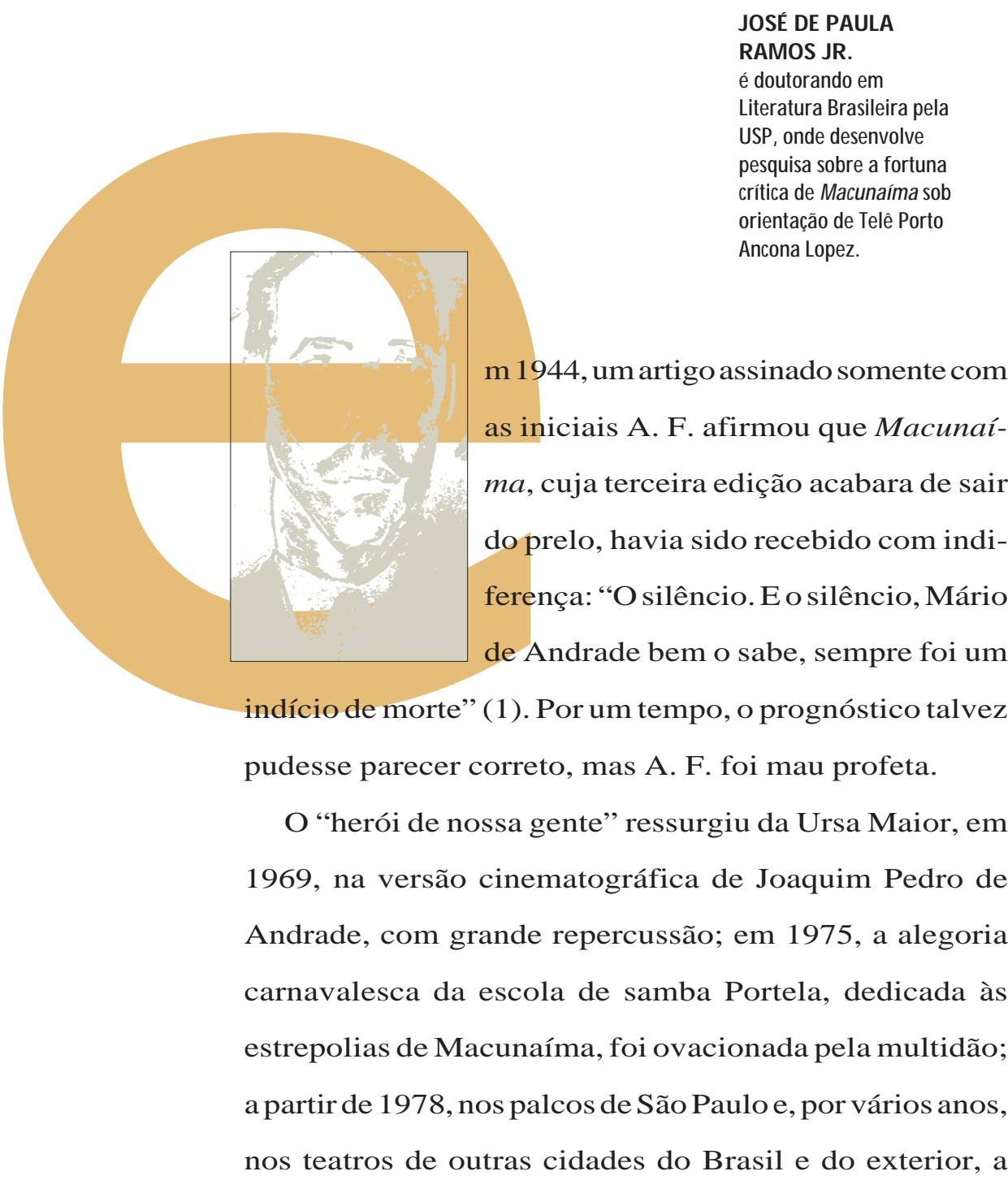

1 A. F., "Livros do dia/ 'M acunaíma', de Mário de An. drade", in A Manhã, Rio de Janeiro, 1 $\% \mathrm{dez} / 1944$. 
2 M. Cavalcanti Proença, Roteiro de M a cunaíma, 1 à ed., São Paulo, Anhembi, 1955. Reeditado em 1969, 1974 1977 e 1978, a partir da 2 ed., Rio de Janeiro, C ivilizaçã̃o Brasileira.

3 "M acunaíma. 0 Livro de Mário de Andrade", in Diário $\mathrm{N}$ acio nal, São Paulo, 7 / ago./ 1928.

4 Silviano Santiago, "A Trajeto ria de um Livro", in Mário de Andrade, Macunaíma, o Herói sem $N$ enhum Caráter, edição crítica coordenada por Tele Porto Ancona Lopez, 2ạ ed., 1 reimp. Madrid/São Paulo, AแC AXX/ Scipione, 1997, pp. 182-93. Coleccíon Archivos 6 (1 a ed., 1988). Esse ensaio foi reunido em Silviano Santiago, $N$ as M alhas da Letra, São Paulo, Cia. das Letras, pp. 124 39, 2 a ed., Rio de Janeiro, Rocco, 2002, pp. 145.63, com o título mudado para "História de um Livro".

5 Tristão de A taíde [Alceu Amo roso Lima], "M a cunaíma", in 0 Jornal, Rio de Janeiro, 9/ set/ 1928, p. 4.

6 os dois prefácios foram publicados em: M arta Rossetti Batis ta, Telê Porto Ancona Lopez e Yone Soares Lima, Brasil: 19 Tempo Modernista - 1917/ 29, São Paulo, IEB.USP, 1972 pp. 289.95 . transcriação cênica de Jacques Thieriot, do Grupo Pau Brasil e de Antunes Filho alcançou um sucesso magnífico. Embora com repercussão discreta, as artes plásticas também contribuíram para a divulgação da rapsódia, com valiosas ilustrações de Pedro Nava, Tarsila do Amaral, Cícero Dias, Carybé, Arlindo Daibert e Rita Loureiro. As peripécias do imperador do mato-virgem inspiraram até mesmo história para revista em quadrinhos e adaptação para a literatura infantil. Macunaíma conquistou um sem-número de novos leitores por meio dessas manifestações artísticas derivadas.

O fato decisivo, porém, para a incorporação estável de Macunaíma ao repertório cultural brasileiro e a conquista de um contingente enorme de leitores, foi a inclusão sistemática da obra em exames para ingresso em universidades, prática disseminada pelo país desde, ao menos, a década de 1980. De lá para cá e cada vez mais intensamente, incontáveis vestibulandos e colegiais têm lido Macunaíma, cujas edições se sucedem, algumas em tiragens populares, vendidas em bancas de jornais a preço módico. A rapsódia de Mário de Andrade tornou-se um fenômeno editorial e, atualmente, uma consulta rápida da palavra "Macunaíma" na Internet registra mais de 50.000 resultados em sites do país. Sob o critério numérico da população do Brasil comparada ao seu leitorado, não se pode dizer que a obra se tornou verdadeiramente popular, mas atravessa há décadas uma tsunami de popularização e a sua irradiação no imaginário nacional é irreversível.

Quanto à recepção crítica, não é de hoje, Macunaíma é obra reconhecida como um dos pontos mais altos da prosa de ficção brasileira. O enorme prestígio atual da rapsódia, porém, é marcado por uma trajetória acidentada, que pode ser dividida em duas fases.

O primeiro período se estende de 1928 , ano da primeira edição da rapsódia, até 1954, ano anterior à publicação do Roteiro de Macunaíma, de M. Cavalcanti Proença (2), marco inicial da fase seguinte. Nesses 26 anos, que compreendem as três edições publicadas em vida do autor (1928, $1937 \mathrm{e}$
1944), prevalece a crítica periodista, mas nem sempre de caráter marcadamente jornalístico, uma vez que muitos trabalhos propendem ao ensaísmo, sendo que alguns são ensaios propriamente.

A primeira recepção pública deu-se no Diário Nacional, na edição de 7 de agosto de 1928. Trata-se de uma resenha curta, mas densa, que sintetiza aspectos decisivos para a compreensão da obra. O resenhista identifica o aproveitamento de material mítico amazônico na composição do enredo e na criação de personagens; observa, também, a mistura desse material com "outras lendas brasileiras [...], manifestações de costumes, superstições, provérbios, modismos vocabulares, frases feitas e cacoetes brasileiros" (3).

Além de apresentar uma visão geral do enredo, tão sumária quanto aguda, o articulista informa que o romance "satiriza certos defeitos do brasileiro" e que é "uma sátira um pouco crua para poder cair nas mãos de qualquer pessoa”. Há, ainda, uma ligeira referência ao narrador complexo de Macunaíma, uma vez que, diz o articulista, a narrativa é veiculada por um “autor”, que a aprendera de um papagaio, que, por sua vez, a ouvira do próprio protagonista, o "herói sem nenhum caráter".

Numa demonstração de notável segurança crítica perante algo tão inusitado, que tanto se aproveitara do repertório mítico e folclórico do Brasil, a resenha termina por avaliar Macunaíma como "uma das obras mais originais da nossa literatura”. Não há identificação de autoria dessa primeiríssima recepção a Macunaíma. Silviano Santiago (4) supõe que ela seria do próprio Mário de Andrade.

O segundo pronunciamento sobre a obra coube a Alceu Amoroso Lima, em longo artigo assinado com o pseudônimo Tristão de Ataíde (5). Mário de Andrade confiara ao crítico dois prefácios que escrevera para a sua obra, mas que decidira manter inéditos (6). Com esse material em mãos, Tristão de Ataíde pôde destacar com precisão questões como o "senso de nacionalismo orgânico e social", o processo de "desregionalização”, a invenção lingüística, certas 


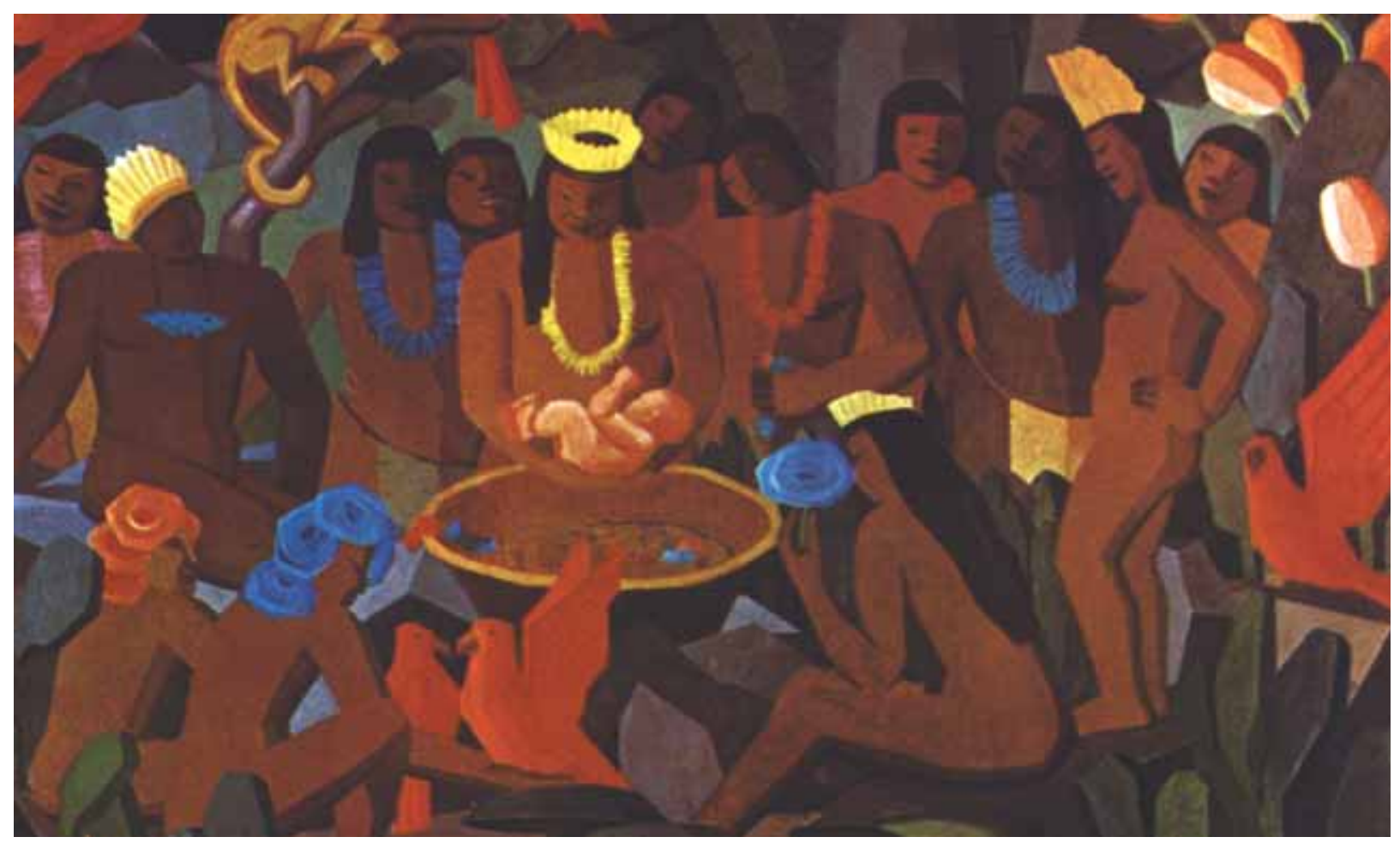

relações entre arte erudita e arte popular, o “instintivismo, tão adaptado à mentalidade e às inclinações de nossos dias", além de traços problemáticos do gênero, do herói e da dimensão simbólica de Macunaíma, em conexão com a busca de uma suposta "entidade nacional dos brasileiros" (7).

Tristão de Ataíde fez também restrições ao livro, como ao seu tamanho, tido como "longo demais", além de "cacete muitas vezes, como na imensa carta, em estilo médico-purista, que o nosso herói escreve às suas súditas do Uraricoera". De acordo com seu catolicismo militante, o crítico viu no livro "uma pornografia muitas vezes dispensável" e, no "herói sem nenhum caráter", um "modelo do que devemos combater em nós".

O texto de Tristão tornou-se famoso, entre outros motivos, por inaugurar uma polêmica que ainda hoje produz eventuais atritos na crítica. Trata-se das relações entre Macunaíma e o movimento da antropofagia, desencadeado por Oswald de Andrade. Tristão, valendo-se de uma carta de Mário de Andrade dirigida a ele, dissociou a rapsódia do movimento liderado por Oswald. É importante lembrar que a Revis- ta de Antropofagia reproduziu em seu segundo número parte do primeiro capítulo da narrativa, que, então, ainda estava no prelo, com o título de "Entrada de Macunaíma”. Oswald de Andrade aceitou a provocação de Tristão e reivindicou Macunaíma para a antropofagia.

Polêmica à parte, Oswald destacou pontos fundamentais para o conhecimento crítico da obra de Mário, como a aproximação com a Odisséia, que convida a uma reflexão sobre o gênero e pressupõe um diálogo com a alta tradição épica e mítica da narrativa ocidental. Ao discernir a invenção do "herói cíclico e por cinquienta anos [d]o idioma poético nacional" (8), Oswald tocou em pontos que exigem atenção especial, como a questão da (in)definição de um caráter nacional brasileiro, supostamente firmado no princípio da "posse contra a propriedade" (9).

O polígrafo João Ribeiro, respeitado acadêmico da velha geração e folclorista notável, foi contundente ao considerar Macunaíma uma asneira: "Mário de Andrade é capaz de uma asneira, mas sempre uma asneira respeitável. E, nesse caso, uma asneira de talento" (10). O elogio é

\section{B atizado de}

M acunaíma, de T arsila do

A maral

7 Primeiro prefácio, op. cit, $p$ 289

80 swald de Andrade, "Esque ma ao Tristão de Ataíde", in Revista de Antropofagia, São Paulo, a. I, n- 5, set/ 1928 p. 3.

9 Idem, ibidem

10 João Ribeiro, "Crônica Literá. ria/ Macunaíma - Herói sem $N$ enhum $C$ aráter - por M ário de Andrade", in fornal do Bra sil, Rio de Janeiro, 31/ out./ 1928, p. 10. Reunido em João Ribeiro, O s Modernos, Rio de Janeiro, Academia Brasileir de Letras, 1952, pp. 8184 


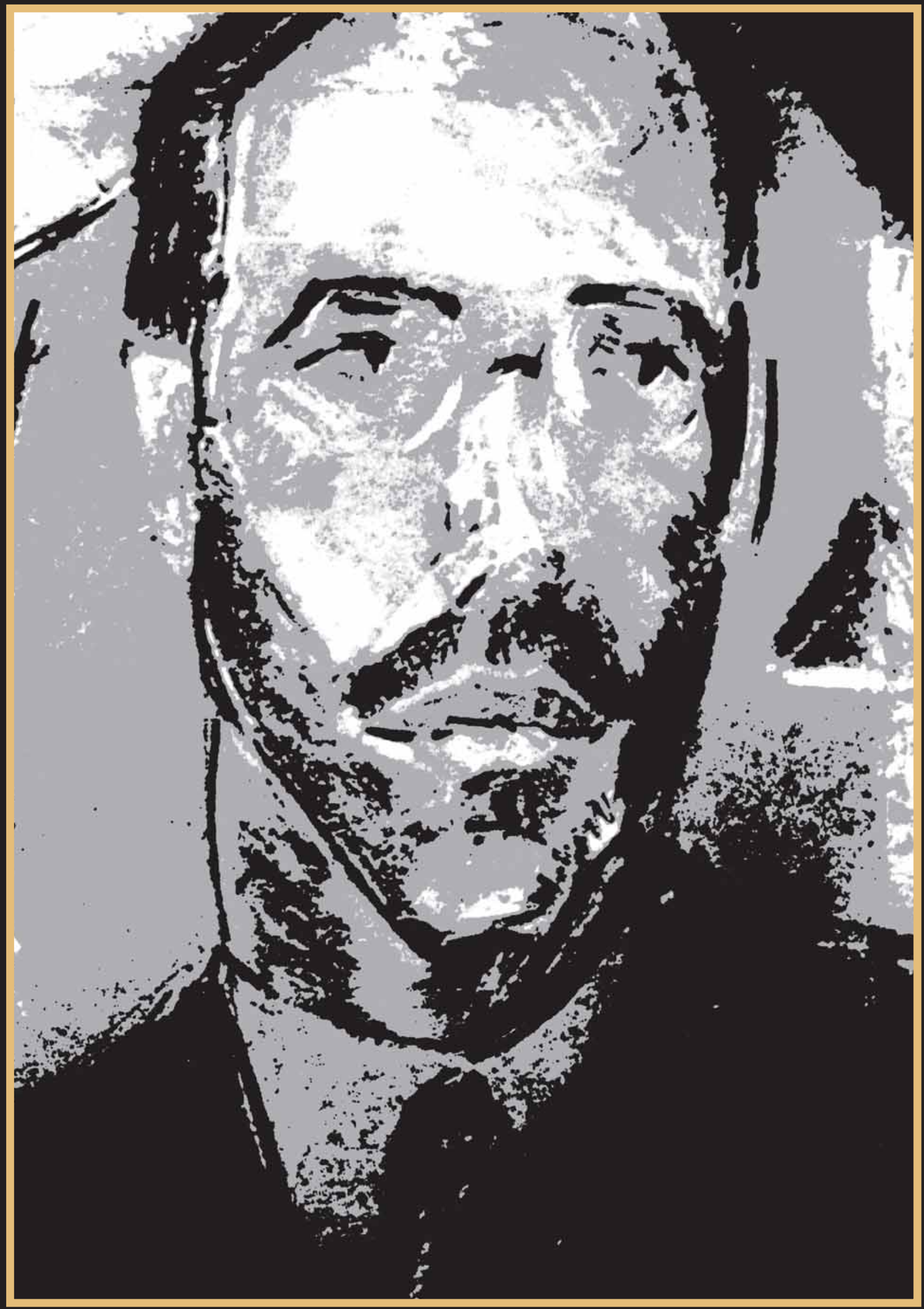


corroído pelo sarcasmo: "Se Macunaíma fosse um livro de estréia, o autor nos causaria pena como a de um próximo hóspede de manicômio". Não obstante o juízo negativo, o artigo de João Ribeiro suscita grande interesse por aquilo que soube constatar, sem saber compreender: a originalidade de Mário perante o material de que se valeu; o caráter compósito do herói, que estaria mais próximo de Malasartes, tido como epigonia ibero-cabocla de Ulisses, do que da "figura do Macunaíma da lenda amazônica"; a estrutura fragmentária e contraditória das personagens e da narrativa; a subversão espaço-temporal por meio da assumida imitação da perspectiva mágica, própria do mito; enfim, a função do humor. João Ribeiro hesita na classificação do gênero - "romance (se acaso é romance)" - e nega unidade à obra, por suposta falha do artista: "É um livro voluntariamente bárbaro, primevo, espécie de fragmentos desconexos que escaparam e foram reunidos por um comentador reduzido à inépcia de qualquer coordenação”.

Outro crítico veterano, de muito prestígio, que se interessou por Macunaíma logo no primeiro momento foi Nestor Vítor (11). Após discutir a legitimidade do indianismo na literatura brasileira, o crítico atribui a Macunaíma o caráter de obra fundadora de "um neo-indianismo derrotista", que ele considerou lamentável na medida em que "o índio, visto com tão furioso freudismo, torna-se símbolo antecipado da nossa segura bancarrota como povo no correr dos séculos". Nestor Vítor viu em Macunaíma o exemplo patente de um "movimento literário dionisíaco de arremedo", impregnado de dadaísmo e da "ciência de Freud", a ponto de fazer do processo onírico, em que as dimensões e os limites naturais dão lugar às possibilidades do maravilhoso, o princípio estrutural da narrativa. Nestor Vítor entendeu que esse processo, “próprio à criança e ao homem primitivo", como ensinava a etnologia positivista, seria "um modo de pensamento regressivo" levado ao último grau por Mário de Andrade. O texto de Nestor Vítor é outro exemplo de crítica adversa, embora respeitosa (ao contrário de João
Ribeiro), riquíssima em sugestões críticas. Foi ele, por exemplo, o primeiro a associar Macunaíma à tradição literária que inclui os "contos orientais, as lendas da Idade Média, Gargantua e Pantagruel, de Rabelais, Peer Gynt, de Ibsen [...]."

Silviano Santiago (12) tem como modesta a repercussão de Macunaíma na década de 1920. No entanto, se considerarmos que, para Macunaíma, essa década tem somente dois anos e meio, e que nesse período a obra mereceu, no mínimo, vinte e dois pronunciamentos de críticos importantes, distribuídos em publicações de cinco estados, talvez a repercussão não tenha sido tão modesta assim.

De 1931 a 1954, a crítica retomou pontos levantados pelas considerações pioneiras, examinando-os, discordando ou concordando com eles, acrescentando-lhes novos matizes e propondo, às vezes, novos atalhos de leitura. Tal produção agregou autores da importância de Luís da Câmara Cascudo, Ronald de Carvalho, Sérgio Milliet, Sérgio Buarque de Holanda, Brito Broca, Nelson Werneck Sodré, Rubem Braga, Roger Bastide e Florestan Fernandes. Este último merece menção especial por seu estudo "Mário de Andrade e o Folclore Brasileiro" (13). Embora de interesse mais amplo, pois discute a posição de Mário de Andrade no âmbito dos estudos folclóricos no Brasil e compreende o conjunto de sua produção intelectual e artística, esse ensaio inaugura uma postura crítica mais rigorosa no exame das relações entre cultura popular e cultura erudita, decisivas para a compreensão da obra de Mário de Andrade, especialmente de Macunaíma. Essa leitura mais minuciosa e exigente de Florestan Fernandes prenuncia a segunda fase da fortuna crítica da rapsódia, inaugurada pela publicação do primeiro livro dedicado inteiramente ao seu estudo, o Roteiro de Macunaíma, de M. Cavalcanti Proença. Aliás, trata-se, porventura, do primeiro livro inteiramente dedicado à investigação de uma obra modernista (14).

A obra de Cavalcanti Proença é ponto de chegada da primeira fase da história da fortuna crítica de Macunaíma e ponto de
Na página

anterior,

retrato

de Mário de

Andrade, por

A nita M alfatti
11 N estor Vítor, "Macunaíma, o Herói sem N enhum Caráter", in $0 \mathrm{Globo}$, Rio de Janeiro, 8/ out./ 1928. Reunido em $\mathrm{N}$ estor Vítor, "Os de Hojel Mário de Andrade/ Macunaíma", in 0 bra Crítica de N estor Vitor, Rio de Janeiro, MEC/ Fundação $C$ asa de Rui Barbo sa, 1973, v. II, pp. 360-5 (1 ed. 1938).

120 p. cit.

13 Florestan Fernandes, "Mário de Andrade e o Folclore Brasileiro", in Revista Arquivo M unicipal, São Paulo, a no XII, no 106, jan.fev./ 1946, pp. 135-58. Reproduzido em: Revista Arquivo M unicipal, São Paulo, n 198, 1990, pp. 135-58. Edicão fac-similar do no 106 , 1946, da mesma revista.

14 Devo essa observação a Telê Porto Ancona Lopez. 
15 Telê Porto Ancona Lopez, "A Margem e o Texto: Contribuicăo para 0 Estudo de $\mathrm{MaCu}$ naíma", in Boletim Bibliográfico Biblioteca M unicipal "Mário de Andrade", São Paulo, no espe cial, fev./ 1970, pp. 9-81. Depois, publicado em M acuna ma: a Margem e o Texto, São Paulo, Secretaria C ultura, Espor te e Turismo/ Hucitec, 1974.

16 Mário de Andrade, Macunaíma, edição crítica de Telê Porto Ancona Lopez, Rio de Janeiro/ São Paulo, Luvros Técnicos Científicos/ Secretaria da Cultora, Ciência e Tecnologia, 1978.

170 p. cit.

18 Haroldo de Campos, Morfolo gia do M a cunaíma, São Paulo Perspectiva, 1973.

19 M ário Chamie, Intertexto: Escrita Rapsódica - Ensaio de Leitura Produtora, São Paulo, Práxis, 1970

20 Maria Susana Camargo, Ma cunaíma - Ruptura e Tradição São Paulo, M assa 00 hno/ João Farkas, 1977.

21 G ilda de M ello e Souza, 0 Tup e o Alaúde: uma Interpretação de M acunaíma, São Paulo, Duas Cidades, 1979

22 Eneida Maria de Souza, A Pe dra Mágica do Discurso, 2a ed revista e ampliada, Belo Horizonte, Ed. UFM G, 1999.

23 Raúl Antelo, $\mathrm{N}$ a llha de Mara patá, São Paulo/Brasília, Hucitec/ M IN C / Pró-M emória/ IN L, 1986.

24 M ario M. G onzález, "M acuna ma", in A Saga do Anti-heró São Paulo, N ova Alexandria/ Embaixada de Espanha, 1994 pp. 297-314

25 Mário Andrade e Manuel Bandeira, Comespondência Mário de Andrade \& M anuel Bandeira, organização, introdução e no tas M arcos Antonio de M oraes. 1 à ed., São Paulo, Edusp/ IEB, 2000 (2@ ed., 2001).

26 Lélia Coelho Frota (org.), Carlos e Mário: Correspondência entre Carlos Drummond de Andrade - Inédita - e Mário de Andrade, a presentação e notas às cartas de Mário de Andrade: Carlos Drummond de Andrade; prefácio e notas às cartas de Carlos Drummond de Andrade: Silviano Santiago, Rio de Janeiro, Bem-Te-Vi, 2002.

27 Mário de Andrade, 0 Turista Aprendiz, estabelecimento de texto, introdução e notas de Telê Porto Ancona Lopez, 1ㄹe ed., São Paulo, Duas Cidades/ Secreta ria Ciência, Cultura e Tecnolo gia, 1976 (2a ed., 1983).

28 Darcy Ribeiro, "Liminar/ Macunaíma", in Mário de Andrade, Macunaíma, edição crítica de Telê Porto Ancon Lopez (coord.), op. cit, p. XVIII. partida da segunda. O Roteiro sintetiza as especulações centrais da fase periodista e realiza a primeira exegese sistemática da rapsódia, abrangendo campos variados como a filologia, a estilística, a hermenêutica, a crítica e a história literária.

A obra admirável de Cavalcanti Proença, por um tempo, pareceu esgotar a matéria. Até a sua segunda edição, em 1969, o assunto Macunaíma continuou a frequientar páginas de periódicos, mas com frequiência escassa.

De 1970 em diante, acentua-se o processo de enriquecimento da fortuna crítica de Macunaíma, com farta produção universitária, teoricamente fundamentada e desenvolvida com rigor metodológico. Talvez, por sua especificidade acadêmica, no sentido de trabalho científico, essa produção devesse ser considerada como uma terceira fase da recepção crítica de Macunaíma. Pelos avanços que trouxeram, algumas obras desse período tornaram-se referências obrigatórias a quem deseje compreender a obra-prima de Mário de Andrade e o seu alcance.

Telê Porto Ancona Lopez, com $M a-$ cunaíma: a Margem e o Texto (15), inaugurou a sua "contribuição para o estudo de Macunaíma", que se estenderia a toda a obra de Mário de Andrade, de tal modo que seu nome e o dele estão para sempre conjugados. Deve-se à pesquisadora a continuidade, o alargamento e o aprofundamento do trabalho de M. Cavalcanti Proença. A Margem e o Texto rastreou minuciosamente o percurso criativo da rapsódia, preparando o terreno para a edição crítica da mesma, cuja primeira versão foi publicada em 1978 (16). Dez anos depois, essa foi aprimorada na exemplar publicação da Coleção Archivos (17), que alia a perspectiva de edição crítica à de edição genética e conta com a colaboração de vários estudiosos que se pronunciaram de modo relevante sobre a obraprima de Mário de Andrade.

Recuando um pouco no tempo, é necessário consignar que Morfologia do Macunaíma (18), de Haroldo de Campos, e Intertexto (19), de Mário Chamie, trouxeram novas luzes. O primeiro aplicou o mé- todo do módulo fabular, colhido nos estudos de Vladimir Propp, para um trabalho de análise estrutural da narrativa; o segundo, apoiado na lingüística, procurou apreender as matrizes estruturais da rapsódia, vinculadas à noção de "sátira menipéia", além de introduzir noções críticas de Bakhtin como as de "dialogismo" e "polifonia", caminho desenvolvido mais tarde por Susana Camargo (20). Gilda de Mello e Souza, com O Tupi e o Alaúde (21), polemizou com Haroldo de Campos e propôs uma instigante leitura interpretativa de Macunaíma, aproximando-a à novela de cavalaria medieval, sobretudo à Demanda do Santo Graal e ao modelo compositivo criador da música popular de nossos cantadores.

Eneida Maria de Sousa empreendeu uma análise semiológica preocupada com a "prática discursiva, entendida enquanto articulação entre sujeito e linguagem" (22), aproximando-se de formulações de Bakhtin sem descartar a abordagem estrutural, cuja raiz está em Lévi-Strauss. Relações entre Macunaíma e o universo latino-americano foram estudadas por Raúl Antelo (23); Mario M. González (24) examinou vínculos possíveis entre a rapsódia de Mário de Andrade e a narrativa picaresca espanhola.

Muitos outros estudos foram apresentados em dissertações de mestrado e em teses, novos ensaios são divulgados em livros ou revistas especializadas, novas pesquisas são empreendidas, outros preciosos subsídios à matéria surgem nas publicações da correspondência de Mário de Andrade, como os trabalhos modelares de Marcos Antonio de Moraes (25) e de Lélia Coelho Frota (26), ou com a publicação de inéditos como O Turista Aprendiz (27), por Telê Porto Ancona Lopez. E não mencionamos estudos que se acumulam lentamente no exterior, interessados no "herói de nossa gente". Tudo indica que a fortuna crítica de Macunaíma, já bem consistente, tende a multiplicar-se mais ainda, pois a rapsódia do "herói sem nenhum caráter" continua a repor o seu enigma a cada releitura. Apesar de tantos esforços críticos reveladores, como disse Darcy Ribeiro, “Macunaíma permanece um mistério” (28). 